\title{
Amplification of Transducer Gain by Angiotensin II- Mediated Enhancement of Cortical Actin Density in Osmosensory Neurons
}

\author{
Zizhen Zhang and Charles W. Bourque \\ Centre for Research in Neuroscience, McGill University and Montreal General Hospital, Montreal, Quebec, Canada H3G 1A4
}

\begin{abstract}
Osmosensory neurons transduce osmotic signals into a neural spike code that commands behavioral and endocrine responses that mediate body fluid homeostasis. Although changes in osmoregulatory reflex gain are known to occur under physiological and pathological conditions, the basis for this modulation is unknown. Here, we show that angiotensin II amplifies osmosensory transduction by enhancing the proportional relationship between osmolality, receptor potential, and action potential firing in rat supraoptic nucleus neurons. This effect is mediated by a phospholipase $\mathrm{C}$ - and protein kinase $\mathrm{C}$-dependent increase in cellular mechanosensitivity that is associated with a rapid increase in cortical actin filament density. Preventing this increase with cytochalasin D eliminated the enhancement of mechanosensitivity, whereas enhancing actin filament density with jasplakinolide potentiated mechanosensitivity and occluded the effects of angiotensin II. These results indicate that a receptor-mediated increase in cortical actin density can enhance osmosensitivity in acutely isolated supraoptic neurons.
\end{abstract}

Key words: actin; angiotensin II; cytoskeleton; osmotic pressure; osmosensitivity; supraoptic nucleus; vasopressin

\section{Introduction}

Osmosensory neurons play a fundamental role in the control of extracellular fluid (ECF) osmolality. In mammals, these neurons detect small changes in ECF osmolality and transduce them into proportional changes in action potential firing rate. This neural spike code is relayed to effector neurons that modulate the intake and excretion of salt and water in a manner that promotes osmotic homeostasis (Bourque et al., 2007; Bourque, 2008). Previous studies have shown that the osmotic control of osmoregulatory responses can be modulated under various physiological conditions. For example, the slope of the relationship between plasma osmolality and vasopressin (VP) (antidiuretic hormone) secretion is potentiated by hypovolemia or hypotension and is attenuated by hypervolemia or hypertension (Dunn et al., 1973; Robertson and Athar, 1976; Robertson et al., 1976). Although this modulation of osmoregulatory gain plays a key role in the coordination of cardiovascular and hydromineral homeostasis (Verbalis, 2003), the basis for this modulation is unknown.

Previous studies have shown that neurons in the subfornical organ project axons into the supraoptic nucleus (SON) (Renaud

Received April 7, 2008; revised July 31, 2008; accepted Aug. 18, 2008.

This work was supported by Canadian Institutes of Health Research Operating Grant MOP-9939 and by a James McGill Research Chair (C.W.B.). Z.Z. was a recipient of Studentship Awards from the McGill University Health Center Research Institute and the Heart and Stroke Foundation of Canada. The Research Institute of the McGill University Health Centre receives support from Fonds de la Recherche en Santé du Québec.

Correspondence should be addressed to Dr. Charles W. Bourque, Division of Neurology, Montreal General Hospital, 1650 Cedar Avenue, Room L7-216, Montreal, Quebec, Canada H3G 1A4. E-mail: charles.bourque@mcgill.ca.

Z. Zhang's present address: Montreal Neurological Institute, 3801 University Street, Montreal, Quebec, Canada H3A 2 B4.

DOI:10.1523/JNEUROSCI.1495-08.2008

Copyright $\odot 2008$ Society for Neuroscience $\quad$ 0270-6474/08/289536-09\$15.00/0 et al., 1983; Wilkin et al., 1989), where they excite the magnocellular neurosecretory cells (MNCs) that release vasopressin from the neurohypophysis (Sgro et al., 1984). In vivo, subfornical organ neurons are activated by hypovolemia (Ishibashi et al., 1985; Potts et al., 2000) and hypotension (Nicolaidis et al., 1983), suggesting that this neural pathway contributes to the potentiation of osmotically evoked vasopressin release under these conditions. Subfornical organ neurons projecting to the supraoptic nucleus contain angiotensin II (Ang II) (Nicolaidis et al., 1983), a peptide known to mediate the excitation of MNCs during electrical stimulation of the subfornical organ (Jhamandas et al., 1989). However, in addition to these direct excitatory effects, Ang II has been shown to enhance the osmotic activation of MNCs (Akaishi et al., 1980; Sladek et al., 1982), and mice lacking the Ang II type-1 $\left(\mathrm{AT}_{1}\right)$ receptor show attenuated vasopressin release during hyperosmolality compared with wild-type mice (Morris et al., 1999). Thus, Ang II may amplify osmoregulatory gain by an effect in the supraoptic nucleus.

The excitation of MNCs under hypertonic conditions is attributable in part to their intrinsic osmosensitivity (Mason, 1980; Voisin and Bourque, 2002; Bourque et al., 2007). When exposed to an increase in osmolality MNCs generate a depolarizing receptor potential that promotes an increase in the rate of action potential discharge (Oliet and Bourque, 1993). This osmoreceptor potential is mediated by the mechanical activation of $\mathrm{Gd}^{3+}$ sensitive, stretch-inhibited, cation (SIC) channels during hyperosmotic shrinking (Oliet and Bourque, 1996). Interestingly, Ang II has been shown to increase the probability of opening of SIC channels and to enhance the excitatory response of isolated MNCs to hyperosmotic stimuli (Chakfe and Bourque, 2000). Although the basis for this effect is not known, a recent study has 

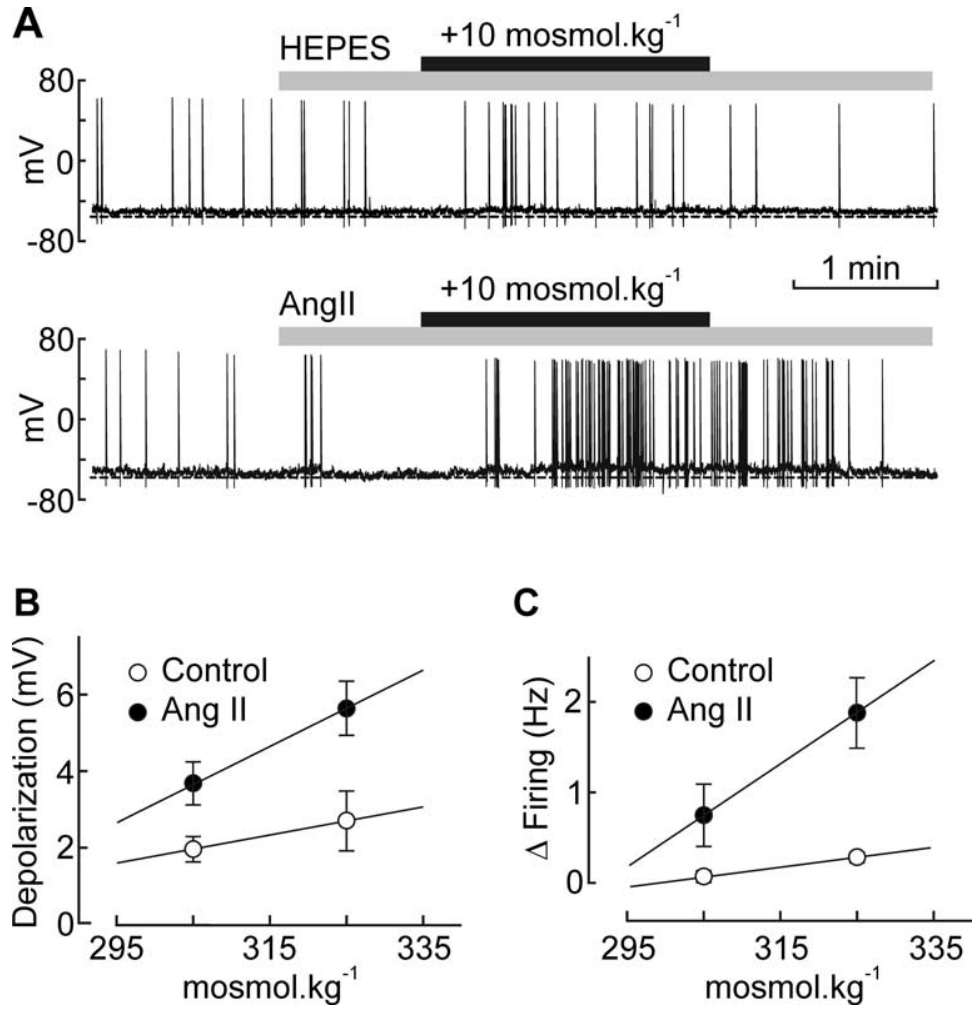

Figure 1. Ang Il increases osmosensory gain in MNCS. A, Examples of voltage recordings obtained from isolated MNCs exposed to a +10 mosmol $\cdot \mathrm{kg}^{-1}$ hyperosmotic stimulus (black bar) in the absence (top) or presence (bottom) of $10^{-7} \mathrm{M}$ Ang II (gray bar). $\boldsymbol{B}$, Graph plotting the mean ( \pm SEM) osmoreceptor potentials (depolarization) induced by osmotic stimuli applied in the absence and presence of Ang II. The solid lines are linear regressions through data points. C, Graph plotting the mean ( \pm SEM) changes in firing rate ( $\Delta$ firing) induced by osmotic stimuli applied in the absence and presence of Ang II. The lines are linear regressions through data points.

shown that the osmotic modulation of SIC channels varies in proportion with the density of actin filaments (F-actin) (Zhang et al., 2007). We therefore hypothesized that Ang II can amplify osmosensory transduction through a receptor-mediated increase in F-actin density.

\section{Materials and Methods}

Preparation of acutely isolated MNCs. MNCs were acutely isolated from adult $(80-120 \mathrm{~g})$ male Long-Evans rats (Charles River) as described previously (Chakfe and Bourque, 2000; Zhang and Bourque, 2003; Zhang et al., 2007), using a protocol approved by the Animal Care Committee of McGill University and in accordance with the guidelines of the Canadian Council on Animal Care. Briefly, unanesthetized rats were decapitated, and brains were quickly removed from the cranial vault. Coronal slices $(\sim 0.8-1 \mathrm{~mm}$ thick) were cut through the hypothalamus using a razor blade. Tissue blocks $\left(\sim 1 \mathrm{~mm}^{3}\right)$ containing part of the SON were dissected out using iridectomy scissors and were incubated for 90 min at $33.5^{\circ} \mathrm{C}$ in $10 \mathrm{ml}$ of oxygenated $\left(100 \% \mathrm{O}_{2}\right)$ piperazine- $N, N^{\prime}$-bis $(2-$ ethanesulfonic acid) (PIPES)-buffered saline (in mM: $120 \mathrm{NaCl}, 3 \mathrm{KCl}, 1$ $\mathrm{MgCl}_{2}, 20$ PIPES, $1 \mathrm{CaCl}_{2}$, 25 glucose, $\mathrm{pH} 7.0$ and $295 \mathrm{mosmol} \cdot \mathrm{kg}^{-1}$ ) containing $0.7 \mathrm{~g} / \mathrm{L}$ trypsin. Tissue blocks were then washed in trypsinfree oxygenated PIPES solution, $\mathrm{pH} 7.4\left(22^{\circ} \mathrm{C}\right)$ and kept in this solution until used $(0.5-5 \mathrm{~h})$. Single tissue blocks in $\sim 0.5 \mathrm{ml}$ of PIPES solution were triturated with fire polished pipettes, and the resulting suspension was plated onto four to six Petri dishes $(35 \mathrm{~mm})$. Cells were given at least $10 \mathrm{~min}$ to adhere to the plastic before the experiments, which were all performed at room temperature $\left(20-23^{\circ} \mathrm{C}\right)$. Except where specified, cells were perfused with a standard HEPES-buffered solution comprising the following (in mM): $140 \mathrm{NaCl}, 3 \mathrm{KCl}, 1 \mathrm{MgCl}_{2}, 10 \mathrm{HEPES}, 1 \mathrm{CaCl}_{2}, 10$ glucose, $\mathrm{pH}$ 7.4. These chemicals were purchased from Sigma-Aldrich.

Solutions and chemicals. Ang II, chelerythrine (Chel), cytochalasin D
(Cyt-D), phorbol 12-myristate 13-acetate (PMA), and 1,2-bis(2-aminophenoxy)ethane$N, N, N^{\prime}, N^{\prime}$-tetra-acetic acid tetra-potassium (BAPTA) were purchased from Sigma-Aldrich. Jasplakinolide (JSK) and Texas Red-X phalloidin were purchased from Invitrogen. Ang II and Chel were dissolved in water and stored as aliquots at $-20^{\circ} \mathrm{C}$. Cyt-D, PMA, and JSK were dissolved in dimethylsulfoxide (DMSO), and stored as aliquots at $-20^{\circ} \mathrm{C}$. These aliquots were diluted in regular HEPES or PIPES solution immediately before the experiments to yield the final concentrations indicated in the results. Except where specified, DMSO concentration was $\leq 0.1 \%$. In some experiments, 10 mM BAPTA was added in the internal solution for the purpose of chelating internal $\mathrm{Ca}^{2+}$. Texas Red-X phalloidin was dissolved in PBS immediately before the experiments.

Osmometry. Perfusion solutions contained the following (in mM): $75 \mathrm{Na}_{2} \mathrm{SO}_{4}, 3 \mathrm{KCl}, 1$ $\mathrm{MgCl}_{2}, 10 \mathrm{HEPES}, 1 \mathrm{CaCl}_{2}, 10$ glucose, and mannitol (added as needed to bring solutions to the desired osmolality). Cells were first perfused with control (isotonic; $295 \mathrm{mosmol} \cdot \mathrm{kg}^{-1}$ ) solution, and then a step change in osmolality $\left(-60,-30,+30\right.$, or $\left.+60 \mathrm{mosmol} \cdot \mathrm{kg}^{-1}\right)$ was applied for 5 min using a fast stepper device (SF-77B; Warner Instruments), which aligned one of the adjacent barrels of a glass capillary tube assembly that delivered various solutions by gravity at a rate of $1.0 \sim 1.2 \mathrm{ml} \mathrm{min}^{-1}$. Excess solution was removed via a vacuum system. Each cell was tested twice with the same osmotic stimulus, once in control solution and once in solution containing $10^{-7} \mathrm{M}$ Ang II. Ang II was applied beginning $60 \mathrm{~s}$ before and during the 5 min osmotic step. The order of the trials performed on individual cells (i.e., with and without Ang II) was reversed in consecutive recordings, and in each case a 5 min recovery period was interposed between the two trials. The time course of each volume response was compared.

Measurement of cell volume. Relative changes in cell volume [normalized volume $(\mathrm{nV})$ ] were determined as described previously (Zhang and Bourque, 2003). Briefly, images of the cells were captured at their maximal cross sectional area (CSA) using a phase-contrast microscope (Diaphot; Nikon) and a monochrome video camera controlled by Axon Imaging Workbench software (AIW 2.2.0.38; Molecular Devices). For each image, the CSA (in pixels) was determined by tracing the perimeter of the cell using Scion Image for Windows 4.0.2 (Scion Corporation). All values of CSA measured during the control period were averaged $\left(\mathrm{CSA}_{\mathrm{o}}\right)$ and values of $\mathrm{nV}$ at time $t$ (i.e., $\mathrm{nV}_{t}$ ) were calculated from the CSA value at that time point (i.e., $\left.\mathrm{CSA}_{t}\right)$ using the following equation: $\mathrm{nV}_{t}=\left[\left(\mathrm{CSA}_{t}\right)^{3 / 2} /\right.$ $\left.\left(\mathrm{CSA}_{\mathrm{o}}\right)^{3 / 2}\right]$. The time course of volume change was described by fitting changes in $\mathrm{nV}$ as a function of time with monoexponential equations using SigmaPlot 8.0 (SPSS). The time constants and steady-state values obtained by this procedure were used to quantify the responses. Steadystate values of $\mathrm{nV}$ were fitted to the Boyle-van't Hoff osmotic pressure equation: $(\mathrm{nV}=(1 / \pi)[295(1-b)]+b)$, where $\pi$ is the osmolality of the test solution and $b$ is the fraction of the cell content that is osmotically inactive.

Whole-cell patch-clamp recording. Whole-cell voltage-clamp recordings were performed using an Axopatch-1D amplifier (Molecular Devices) using pipettes (1.2 mm outer diameter glass; A-M Systems; 4-5 $\mathrm{M} \Omega$ ) pulled on a P87 Flaming-Brown puller (Sutter Instruments) and filled with internal solution containing the following (in $\mathrm{mM}$ ): 120 K-gluconate, $1 \mathrm{MgCl}_{2}, 10 \mathrm{HEPES}, 1$ EGTA, $4 \mathrm{Na}_{2}$-ATP, $1 \mathrm{Na}$-GTP, 14 phosphocreatine, $\mathrm{pH} 7.2$ and $265 \mathrm{mosmol} \cdot \mathrm{kg}^{-1}$. We found that isolated MNCs swell slightly when patched with pipettes containing isotonic so- 
lutions. This effect, noticeable during timelapse imaging, may be attributable to a small positive hydrostatic pressure retained near the tip of the pipette. We have determined empirically that swelling can be eliminated when cells are patched with internal solutions whose osmolality is $20-30 \mathrm{mosmol} / \mathrm{kg}$ lower than the external medium, presumably by promoting water efflux into the more concentrated solution. Membrane current (d.c.- $2 \mathrm{kHz}$ ) was digitized $(10 \mathrm{kHz})$ via a Digidata $1200 \mathrm{~B}$ interface coupled to a personal computer running pClamp software (version 8.2.0.235; Molecular Devices). In the current-clamp mode, the membrane potential was adjusted to a value $\sim 5$ $\mathrm{mV}$ below action potential threshold and left to stabilize for at least $\sim 3 \mathrm{~min}$ before testing. Under these baseline conditions, resting MNCs fired action potentials at an average rate of $0.4 \pm 0.1 \mathrm{~Hz}(n=29)$. If necessary, a small amount of sustained current (less than $\pm 10 \mathrm{pA}$ ) was injected to adjust the baseline membrane potential of each cell to a value $\sim 5 \mathrm{mV}$ below action potential threshold (i.e., $-50 \pm 5 \mathrm{mV}$ ) before each osmotic stimulus. Because the depolarizing effect of Ang II reaches a maximum after $\sim 30 \mathrm{~s}$ (Chakfe and Bourque, 2000), this procedure was performed 30-40 s after introducing the peptide into the bath (i.e., $20-30 \mathrm{~s}$ before the osmotic stimulus). Cells that were incapable of sustained firing in response to a $1 \mathrm{~s}$ depolarizing current pulse were not used in these experiments. Osmotic stimuli were delivered using the Fast-Step perfusion system (see above). The pressure inside the recording pipette was monitored by a digital pressure gauge (DPM-1B Pneumatic Transducer Tester; Bio-Tek Instruments) connected to the system and was changed as required via a $20 \mathrm{cc}$ syringe.

F-actin staining and confocal microscopy. Cells were fixed by replacing the incubation medium with $4 \%$ paraformaldehyde in $0.1 \mathrm{~m}$ PBS for 20 min. Cells were then washed with PBS containing 1\% Triton X-100 three times for 15 min and covered with PBS containing Texas Red-X phalloidin $(0.165 \mu \mathrm{M}$; Invitrogen) for $20 \mathrm{~min}$ in the dark at room temperature. Cells were subsequently washed with PBS (three times for $20 \mathrm{~min}$ each time) and stored at $4^{\circ} \mathrm{C}$ until imaging was performed. Fluorescence images were acquired by an investigator blinded to the cells treatment with an upright PerkinElmer microscope equipped with a confocal scanner (UltraVIEW LCI Model CSU10-3AX; PerkinElmer Life and Analytical Sciences). Phalloidin-stained cells were illuminated by a $488 \mathrm{~nm}$ line of an argon-krypton laser (Melles Griot 643R; Melles Griot Laser Group) and viewed through a $40 \times, 0.8$ numerical aperture water-immersion objective. The fluorescence emission at $525 \mathrm{~nm}$ was detected using a Hamamatsu Orca ER cooled CCD camera capturing 16 bit images. MetaMorph software (Universal Imaging) was used to analyze digitized images captured at the plane of the maximal CSA. All image capture parameters (laser intensity, camera gain, and exposure time) were fixed throughout the experiments. For line scan analysis of the images, three virtual lines (20 pixels wide) were positioned perpendicular to the membrane $120^{\circ}$ apart from one another. The three fluorescence intensity profiles obtained from each cell were aligned using Microsoft Excel 2003 at the point demarcating background from cell fluorescence, and the profiles of multiple cells were averaged. Values of total cortical fluorescence intensity were obtained by averaging the intensity of a $\sim 2-\mu \mathrm{m}$ thick region traced beneath the membrane along the entire perimeter of the cell using Scion Image.

Statistical analysis. All values in this study are reported as mean \pm SEM. Linear regressions through the data were performed using SigmaPlot 8.0. Comparisons between two means were performed using Student's paired or unpaired $t$ test, as appropriate, and data obtained from multiple groups were compared using one-way ANOVA followed by Dunn's post hoc test (SigmaStat 2.03; SPSS). Slopes of linear regressions were compared using Prism 4.0 (GraphPad Software). Differences were considered significant when $p<0.05$.

\section{Results}

Ang II potentiates osmoreceptor potentials and osmotic spike coding in MNCs

To determine whether Ang II can enhance osmosensory transduction, we obtained whole-cell current-clamp recordings from isolated MNCs and compared the effects of hyperosmotic stimuli $\left(+10\right.$ and $\left.+30 \mathrm{mosmol} \cdot \mathrm{kg}^{-1}\right)$ delivered under control conditions and $60 \mathrm{~s}$ after adding $10^{-7} \mathrm{M}$ Ang II to the perfusion medium. As illustrated in Figure $1 A$, the peptide significantly increased the depolarizing effects of the +10 mosmol $\cdot \mathrm{kg}^{-1}$ (control, $+2.0 \pm 0.3 \mathrm{mV}, n=7$; Ang II, $+3.7 \pm 0.6 \mathrm{mV}, n=11$; $p=0.033$ ) and $+30 \mathrm{mosmol} \cdot \mathrm{kg}^{-1}$ stimuli (control, $+2.7 \pm 0.7$ $\mathrm{mV}, n=5$; Ang II, $+5.6 \pm 0.7 \mathrm{mV}, n=8 ; p=0.016)$. The slope of the relation between membrane depolarization and ECF osmolality was significantly enhanced by Ang II (control, 0.037 $\mathrm{mV} / \mathrm{mosmol} \cdot \mathrm{kg}^{-1}$; Ang II, $0.098 \mathrm{mV} / \mathrm{mosmol} \cdot \mathrm{kg}^{-1} ; p<0.01$ ) (Fig. $1 B$ ). This peptide-induced amplification of osmoreceptor potentials was accompanied by an enhancement of osmotic spike encoding. Indeed, Ang II significantly enhanced the excitatory effects of the $+10 \mathrm{mosmol} \cdot \mathrm{kg}^{-1}$ (control, $+0.07 \pm 0.07 \mathrm{~Hz}, n=$ 7; Ang II, $+0.80 \pm 0.29 \mathrm{~Hz}, n=11 ; p=0.040)$ and +30 mosmol $\cdot \mathrm{kg}^{-1}$ stimuli (control, $+0.28 \pm 0.06 \mathrm{~Hz}, n=5$; Ang II, $+1.88 \pm 0.39 \mathrm{~Hz}, n=8 ; p=0.023)$. Linear regression analysis (Fig. 1C) confirmed that the slope of the relation between changes in firing rate and ECF osmolality was significantly enhanced by Ang II (control, +0.011 Hz/mosmol $\cdot \mathrm{kg}^{-1}$; Ang II, $\left.+0.057 \mathrm{~Hz} / \mathrm{mosmol} \cdot \mathrm{kg}^{-1} ; p<0.05\right)$. Thus, Ang II amplifies osmosensory transduction in isolated MNCs. 
A
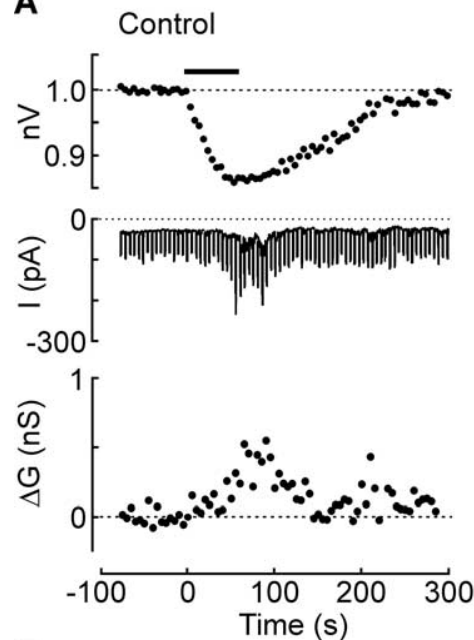

B

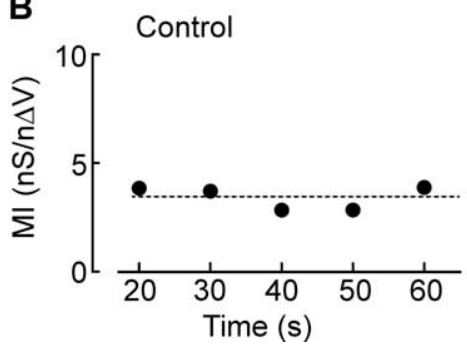

C
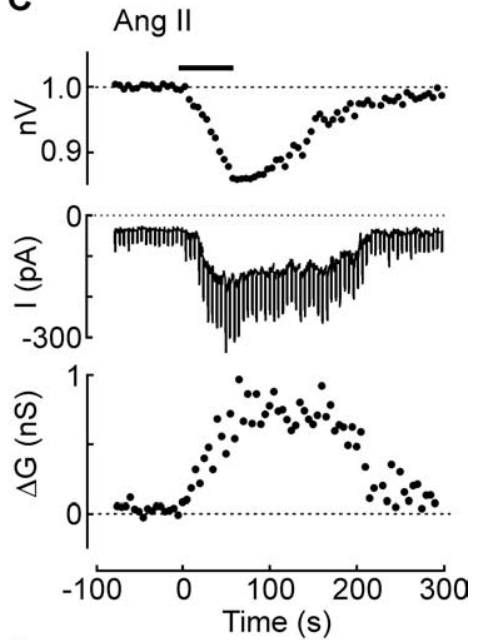

D

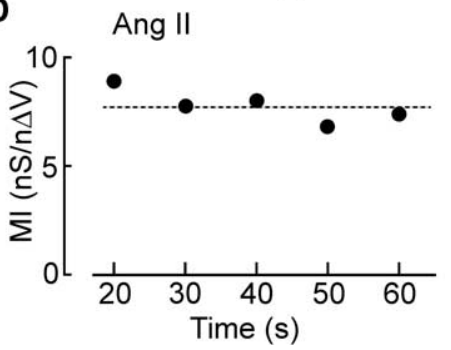

Figure 3. Ang Il increases mechanosensitivity. $\boldsymbol{A}$, Effects of applying negative pressure $(-50 \mathrm{mmHg})$ to the recording pipette for $60 \mathrm{~s}$ (bar) on a cell recorded under control conditions. The top trace shows the change in $\mathrm{nV}$, the middle trace shows the membrane current recorded under voltage clamp $\left(V_{\text {hold }},-60 \mathrm{mV}\right)$. Negative deflections are the current responses $(\Delta /)$ induced by hyperpolarizing steps ( $-40 \mathrm{mV} ; 500 \mathrm{~ms}$ ). The bottom trace shows values of $\Delta G$ computed from measurements of $\Delta /$. B, Plot of the Ml values computed from the data shown in the top traces. The dashed line represents the average of all Ml values computed in this experiment. $C$, Effects of negative pressure $(-50 \mathrm{mmHg})$ on another MNC recorded in the presence of Ang II (same layout as in $\boldsymbol{A})$. Note the larger increases in $\Delta /$ and $\Delta G$. D, Values of $\mathrm{Ml}$ computed from the data shown in $\boldsymbol{C}$.

\section{Ang II does not affect osmometry}

The process of osmosensory transduction involves the effect of ECF osmolality on cell volume (i.e., osmometry) (Zhang and Bourque, 2003) and the mechanical regulation of SIC channels during changes in cell volume (i.e., mechanotransduction) (Oliet and Bourque, 1993; Zhang et al., 2007). To determine whether Ang II affects osmometry, we compared the changes in cell volume evoked by osmotic stimuli ( $5 \mathrm{~min} ;-60,-30,+30,+60$ mosmol $\cdot \mathrm{kg}^{-1}$ ) applied in the absence and presence of Ang II $\left(10^{-7} \mathrm{M}\right.$, introduced $60 \mathrm{~s}$ before the osmotic stimulus). As illustrated in Figure 2, $A$ and $B$, equivalent results were obtained under control conditions and in the presence of Ang II. Indeed, the mean steady-state values of $\mathrm{nV}$ observed at each osmolality were not different when examined in the absence or presence of Ang II $(p>0.05)$ (Fig. $2 C)$. Moreover, as shown in Figure 2D, the time course of volume changes induced by osmotic stimuli were not affected by Ang II $(p>0.05)$. Thus, Ang II does not enhance osmosensory transduction through an effect on osmometry.

\section{Ang II increases mechanosensitivity in MNCs}

To determine whether Ang II enhances the mechanical coupling between changes in cell volume and changes in membrane conductance (Zhang et al., 2007), we quantified this process by calculating the mechanosensory index (MI) of the cells during increases in membrane conductance $(\Delta G)$ induced by cell shrinking evoked by application of negative pressure (approximately $-50 \mathrm{mmHg}$ for $60 \mathrm{~s}$ ) to the recording pipette. This pro- cedure induced uniform changes in cell volume that were similar to those induced by hyperosmolality. Cells were held at -60 $\mathrm{mV}$ under voltage clamp and stepped to $-100 \mathrm{mV}$ every $10 \mathrm{~s}$ (500 ms pulse duration). Membrane conductance at each time point $\left(G_{t}\right)$ was calculated as $G_{t}=\Delta I /$ 0.04 , where $\Delta I$ is the size of the current response to the voltage step. Values of $\Delta G$ at each time point were calculated as $\Delta G=$ $G_{t}-G_{0}$, where $G_{0}$ is the average of the $G_{t}$ values collected during the control period. Because $\Delta G$ increases as a linear function of volume decrease [i.e., as a function of normalized volume decrease $(\mathrm{n} \Delta V)$; where $\mathrm{n} \Delta V=1-\mathrm{nV}$ ] (Zhang et al., 2007), values of MI were computed as $\mathrm{MI}=\Delta G /(\mathrm{n} \Delta V)$. As illustrated in Figure $3 A$, application of negative pressure caused a progressive decrease in volume and a corresponding increase in $\Delta G$. Because values of $\Delta G$ are near zero during the baseline period, MI was only computed once a significant increase in $\Delta G$ was induced (i.e., $20 \mathrm{~s}$ after stimulus onset). As illustrated in Figure $3 B$, values of MI did not significantly vary as a function of time ( $p=0.878$ for 35 cells tested). Thus, for each trial, a single value of MI was calculated by averaging the MI ratios computed at all time points. The mean value of MI measured under control conditions was $3.5 \pm 0.8 \mathrm{nS} / \mathrm{n} \Delta V(n=7)$. As illustrated in Figure 3C, MNCs treated with Ang II displayed suction-induced decreases in cell volume that were equivalent to those observed under control conditions ( $\mathrm{n} \Delta V$ in control, $0.147 \pm 0.015, n=7$; Ang II, $0.140 \pm$ $0.016, n=7 ; p=0.765)$. However, a significantly larger increase in $\Delta \mathrm{G}$ was induced by suction in the presence of Ang II $(+1.0 \pm$ $0.2 \mathrm{nS}$ in Ang II, $n=7$; vs $+0.4 \pm 0.1 \mathrm{nS}$ in control, $n=7 ; p=$ $0.006)$, resulting in a noticeably higher value of MI under those conditions (Fig. $3 B, D$ ). Indeed, the mean value of MI measured in Ang II-treated cells was $8.5 \pm 0.9 \mathrm{nS} / \mathrm{n} \Delta V(n=7)$, a value significantly greater than control $(p<0.05)$.

\section{Increased mechanosensitivity amplifies \\ osmosensory transduction}

To determine whether the potentiation of osmosensory transduction caused by Ang II is attributable specifically to the effect of this peptide on mechanotransduction, we quantified the osmosensitivity of MNCs by measuring their osmosensory index (OI) (computed as for MI) during volume changes induced by hypertonic stimuli delivered in the absence (Fig. $4 A)(n=6)$ and presence of peptide (Fig. $4 B)(n=7)$. Application of a hypertonic stimulus ( $+60 \mathrm{mosmol} \cdot \mathrm{kg}^{-1} ; 5 \mathrm{~min}$ ) provoked a gradual decrease in $\mathrm{nV}$ and increase in $\Delta G$. Although mean steady-state values of $\mathrm{n} \Delta V$ were not different in the two groups (control, $0.142 \pm 0.009 ;$ Ang II, $0.140 \pm 0.009 ; p=0.827$ ), values of $\Delta G$ were significantly greater in Ang II-treated cells (control, $+0.53 \pm 0.16 \mathrm{nS}$; Ang II, $+1.2 \pm 0.2 \mathrm{nS} ; p=0.033$ ). As for MI (Fig. 3), mean values of OI did not vary significantly at different time points during the course of the stimulus $(p=0.745)$. Thus, for each trial a single value of OI was calculated by averaging OI 
scores observed at each time point. As shown in Figure $4 B$, the mean value of OI in Ang II $(8.44 \pm 0.87 \mathrm{nS} / \mathrm{n} \Delta V)$ was significantly greater than that observed in control MNCs $(3.27 \pm 0.78 \mathrm{nS} / \mathrm{n} \Delta V ; p=$ $0.001)$

In agreement with previous observations indicating that osmosensory transduction is mediated by the mechanosensitive modulation of SIC channels (Zhang et al., 2007), values of MI and OI observed under control conditions were not significantly different from each other $(p=$ 0.884) (Fig. 4B). Moreover, Ang II enhanced mean values of $\mathrm{OI}$ and $\mathrm{MI}$ to an equivalent extent ( $p=0.8$ ) (Fig. $4 C$ ). Indeed, when mean values of $\Delta G$ evoked by osmotic or mechanical stimuli are plotted as a function of $\mathrm{n} \Delta V$, we observe that the data sets recorded under control conditions superimpose each other and that Ang II increases the slope of these relations by equivalent amounts (Fig. 4C). Thus, Ang II amplifies osmosensory transduction by enhancing the mechanosensitivity of MNCs.

\section{Ang II increases mechanosensitivity via the phospholipase $\mathrm{C}$-protein kinase C pathway}

Previous studies have shown that $\mathrm{AT}_{1}$ receptors mediate the postsynaptic effects of Ang II on MNCs (Yang et al., 1992; Hatae et al., 2001; Moellenhoff et al., 2001) and that such receptors mediate their effects through the activation of phospholipase $\mathrm{C}$ (PLC) via $\mathrm{G}_{\mathrm{q} / 11}$ (de Gasparo et al., 2000). We therefore incubated MNCs for $20 \mathrm{~min}$ in the presence of $1-[6-[[(17 \beta)-3-$ methoxyester-1,3,5(10)-trien-17-yl] amino]hexyl]-1H-pyrole-2,5-dione (U-73122) (2 $\mu \mathrm{M}$ ), a selective inhibitor of PLC (Bleasdale et al., 1989). As in control conditions, Ang II $\left(10^{-7} \mathrm{M}\right)$ applied to vehicle (DMSO)-treated MNCs significantly increased the MI (DMSO, $2.9 \pm 0.9 \mathrm{nS} / \mathrm{n} \Delta V, n=8$; DMSO plus Ang II, $7.6 \pm 1.4 \mathrm{nS} / \mathrm{n} \Delta V, n=9 ; p=0.021$ ) (Fig. $5 A$ ). However, this effect was significantly inhibited by U-73122 (control, $1.62 \pm 0.47 \mathrm{nS} / \mathrm{n} \Delta V, n=7$; Ang II, $2.1 \pm 0.7 \mathrm{nS} / \mathrm{n} \Delta V, n=8$; $p=0.636)$ (Fig. $5 A$ ).

Activation of PLC causes hydrolysis of $\mathrm{PIP}_{2}$ (phosphatidylinositol 4,5-bisphosphate) into inositol triphosphate and diacylglycerol. The production of diacylglycerol then leads to the activation of protein kinase $\mathrm{C}$ ( $\mathrm{PKC})$, a process which can also require release of $\mathrm{Ca}^{2+}$ from intracellular stores, depending on the PKC isoform involved (Tanaka and Nishizuka, 1994). To examine whether PKC mediates the effects of Ang II on mechanosensitivity, we first examined the effects of PMA, a potent activator of PKC (Tanaka and Nishizuka, 1994). Cells treated with $10^{-7}$ M PMA for 20 min displayed a significantly higher MI than MNCs treated with vehicle alone $(8.3 \pm 1.7 \mathrm{nS} / \mathrm{n} \Delta V$ in PMA, $n=7$; vs $2.8 \pm 0.9 \mathrm{nS} / \mathrm{n} \Delta V$ in DMSO, $n=12 ; p=$ 0.006). We next examined the effects of adding $5 \mu \mathrm{M}$ Chel, a broad-spectrum inhibitor of PKC (Herbert et al., 1990), to the medium filling the patch pipette. After establishing the wholecell configuration, $\sim 3$ min was allowed for solution exchange before MI was measured. In time-matched controls, Ang II significantly enhanced the MI of MNCs (control, $3.0 \pm 0.6$ $\mathrm{nS} / \mathrm{n} \Delta V, n=8$; vs $8.2 \pm 1.1 \mathrm{nS} / \mathrm{n} \Delta V$ in Ang II, $n=9 ; p<$ $0.001)$. However, this effect was inhibited in cells loaded with Chel $(2.0 \pm 0.4 \mathrm{nS} / \mathrm{n} \Delta V$ in Chel, $n=7$; vs $2.3 \pm 0.6 \mathrm{nS} / \mathrm{n} \Delta V$ in Chel plus Ang II, $n=6 ; p=0.653$ ) (Fig. $5 B$ ).

Finally, to determine whether intracellular $\mathrm{Ca}^{2+}$ is required to mediate the effect of Ang II on mechanosensitivity, we examined the effect of including the $\mathrm{Ca}^{2+}$ chelator BAPTA $(10 \mathrm{~mm})$ in the recording pipette. In another group of control cells, Ang II significantly enhanced the mean MI of MNCs from $3.0 \pm 0.9 \mathrm{nS} / \mathrm{n} \Delta V(n=5)$ to $10.2 \pm 1.6 \mathrm{nS} / \mathrm{n} \Delta V(n=6$; $p=0.004$ ) (Fig. 5C). However, when BAPTA was included in the patch pipette, bath application of Ang II could no longer increase mean values of MI $(2.5 \pm 1.1 \mathrm{nS} / \mathrm{n} \Delta V$ in control, $n=$ 8; vs $3.4 \pm 0.8 \mathrm{nS} / \mathrm{n} \Delta V$ in Ang II, $n=6 ; p=0.529$ ) (Fig. $5 C$ ). Thus, Ang II increases the mechanosensitivity of MNCs via the 

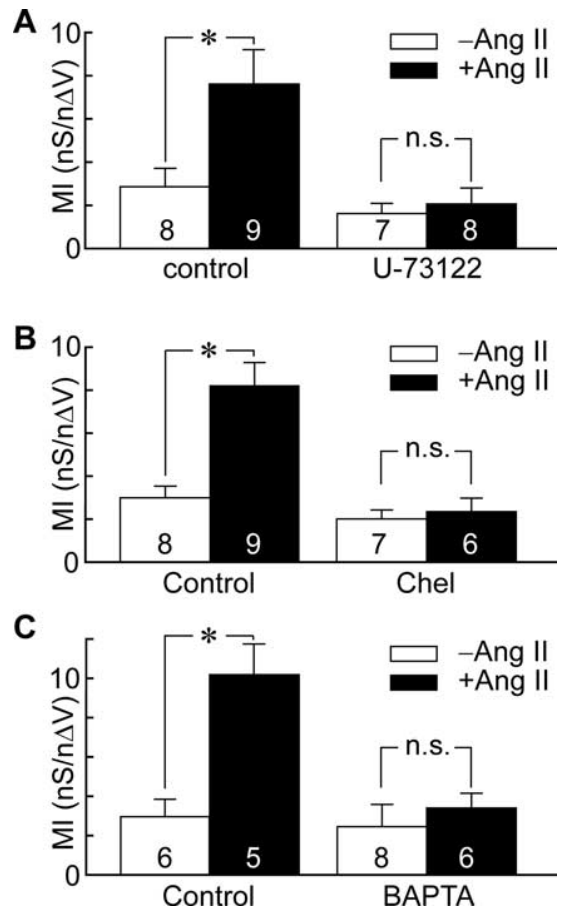

Figure 5. Ang Il potentiates mechanosensitivity via the PLC-PKC pathway. Bar graphs show the mean ( \pm SEM) values of Ml recorded under various conditions. $A$, Values of Ml in control ( - Ang Il; open bars) vs Ang II (+ Ang Il; filled bars) in vehicle (DMSO)-treated cells (Control) and in the presence of the PLC inhibitor U-73122. B, Values of MI observed in the absence ( - Ang II; open bars) and presence ( + Ang Il; filled bars) of Ang II, in cells treated with vehicle (control) or Chel. C, Values of Ml observed in the absence (- Ang II; open bars) and presence (+Ang II; filled bars) of Ang II, in cells patched with normal internal medium (Control) or medium containing $10 \mathrm{~mm}$ BAPTA. ${ }^{*} p<0.05$. n.s., Difference not statistically significant.

PLC-mediated activation of a calcium-dependent form of PKC.

\section{Ang II enhances cortical F-actin density in MNCs}

Osmosensory transduction requires an intact actin cytoskeleton and transducer sensitivity appears to vary in proportion with the amount of F-actin present in the cell (Zhang et al., 2007). Ang II may therefore enhance mechanosensitivity via a PKC-dependent increase in F-actin density. As illustrated in Figure $6 A$, F-actin density was highest along the perimeter of MNCs, and this was visibly greater in Ang II-treated cells than controls. Quantitative line scan analysis indicated that F-actin density is greatest in the $2 \mu \mathrm{m}$ region lying beneath the plasma membrane and that the significant increase in signal caused by Ang II is restricted to the submembrane cortex (Fig. 6B, left panel). A quantification of total cortical fluorescence confirmed that Ang II-treated cells $(n=91)$ show a significantly greater cortical F-actin density than controls (Ang II treated cells, $129 \pm 5 \%$, compared with controls; $n=97 ; p<0.001)$. In contrast, Ang II failed to increase in cortical F-actin density in cells pretreated with Chel $(20 \mu \mathrm{M} ; 15 \mathrm{~min})$ (Fig. 6A, $B$, middle panels). The total cortical fluorescence in cells treated with Chel and Ang II was not significantly greater than in cells treated with Chel alone (Chel plus Ang II, 91.6 $\pm 2.7 \%, n=96$; vs $100.0 \pm 4.2 \%$ for Chel alone, $n=103 ; p=0.125)$. Finally, MNCs treated with $10^{-6}$ M PMA (20 min; $\left.n=91\right)$ displayed significantly greater cortical F-actin density than vehicle (DMSO)-treated cells ( $128 \pm 4 \%$ vs DMSO; $n=99 ; p<0.001$ )
(Fig. 6A, B, right panels). Thus, Ang II causes a PKCdependent increase in cortical F-actin density in MNCs.

\section{Increased F-actin density mediates Ang II potentiation of mechanotransduction}

To examine whether the Ang II-induced increase in cortical F-actin density is necessary to mediate the effect of the peptide on mechanosensitivity, we quantified the effects of Ang II on values of MI in MNCs pretreated with Cyt-D (78 $\mu \mathrm{M} ; 15-30$ min), a drug that depolymerizes F-actin (Cooper, 1987). Ang II applied to vehicle (DMSO)-treated cells significantly increased MI (3.94 $\pm 0.64 \mathrm{nS} / \mathrm{n} \Delta V$ in controls, $n=19$; vs $12.59 \pm 1.92 \mathrm{nS} / \mathrm{n} \Delta V$ in Ang II, $n=18 ; p<0.001$ ) (Fig. $7 A$ ). However, cells treated with Cyt-D were significantly less mechanosensitive than untreated cells (MI of Cyt-D cells, $1.14 \pm 0.99 \mathrm{nS} / \mathrm{n} \Delta V, n=10 ;$ vs $3.94 \pm 0.64 \mathrm{nS} / \mathrm{n} \Delta V$ in DMSO controls, $n=19 ; p=0.021$ ), and they failed to show a significant enhancement of their MI in response to Ang II (MI in Cyt-D plus Ang II, $1.34 \pm 0.97 \mathrm{nS} / \mathrm{n} \Delta V ; n=8 ; p=0.894$ ) (Fig. $7 A)$. Finally, if the increase in F-actin density provoked by Ang II is sufficient to mediate its effect on mechanosensitivity, then enhancing this parameter by other means should occlude the effects of the peptide. To test this hypothesis, MNCs were treated with JSK $(2.5 \mu \mathrm{M} ; 20-30 \mathrm{~min})$, a drug that promotes actin polymerization (Bubb et al., 1994). In a separate set of vehicle (DMSO)-treated controls, Ang II significantly increased MI (3.57 $\pm 0.88 \mathrm{nS} / \mathrm{n} \Delta V$ in controls, $n=6$; vs $9.93 \pm$ $2.26 \mathrm{nS} / \mathrm{n} \Delta V$ in Ang II, $n=6 ; p=0.026$ ). Cells treated with JSK alone were significantly more mechanosensitive than those treated with vehicle alone (MI of JSK cells, $15.89 \pm 2.98$ $\mathrm{nS} / \mathrm{n} \Delta V, n=9$; vs $3.56 \pm 0.88 \mathrm{nS} / \mathrm{n} \Delta V$ in DMSO controls, $n=$ $6 ; p=0.016)$, and they failed to show any additional enhancement of their MI in response to Ang II (MI in JSK plus Ang II, $14.67 \pm 3.53 \mathrm{nS} / \mathrm{n} \Delta V ; n=8 ; p=0.794)$ (Fig. $7 B)$.

\section{Discussion}

Plastic changes in osmosensory gain contribute to body fluid homeostasis

Changes in osmosensory gain play an important role in the central control of body fluid balance. For example, increases in thirst or VP release induced by ECF hyperosmolality are attenuated by concurrent hypervolemia and enhanced by concurrent hypovolemia (Dunn et al., 1973; Robertson and Athar, 1976; Robertson et al., 1976; Verbalis, 2003). These plastic changes in the osmotic modulation of behavioral and endocrine responses are important for fluid homeostasis. Indeed, the net changes in body water accretion caused by these adjustments mediate corrections in ECF volume that are beneficial under such complex physiological conditions. Although changes in osmosensory gain are known to play an important role in the neural control of body fluid balance under both physiological and pathological conditions (Verbalis, 2003), the mechanisms by which gain is regulated have remained unknown.

\section{Ang II increases the intrinsic osmosensitivity of MNCs}

A body of evidence indicates that Ang II is released into the SON during hypovolemia (Renaud et al., 1983; Sgro et al., 1984; Ishibashi et al., 1985; Jhamandas et al., 1989; Wilkin et al., 1989; Potts et al., 2000), where it can enhance the osmotic control of VP releasing MNCs (Akaishi et al., 1980; Sladek et al., 1982; Morris et al., 1999; Chakfe and Bourque, 2000). The 
osmotic control of electrical activity and $\mathrm{VP}$ release by MNCs in vivo is mediated by a variety of factors; including synaptic afferents originating from central and

peripheral osmosensory neurons (Bourque et al., 2007), the osmotic control of taurine release from astrocytes (Hussy et al., 2000), and the intrinsic osmosensitivity of the MNCs (Voisin and Bourque, 2002). Changes in the sensitivity of the relationship between VP release and ECF osmolality, therefore, could be mediated by actions on any combination of these processes (Voisin and Bourque, 2002). Our results indicate that Ang II potentiates the relationship between ECF osmolality and spike coding by increasing the amplitude of the depolarizing osmoreceptor potentials generated in response to hyperosmotic stimuli (Fig. $1 B$ ). Although these results do not exclude the possibility that Ang II might modulate other factors responsible for the osmotic control of MNCs, they provide clear evidence that Ang II can enhance osmosensory gain by amplifying osmosensory transduction.

\section{Ang II enhances osmosensory gain by amplifying mechanosensitivity}

Osmosensory transduction occurs in two steps: osmometry (Zhang and Bourque, 2003) and mechanotransduction (Oliet and Bourque, 1993; Zhang et al., 2007). The modulation of this process could therefore be mediated by effects on either or both of these steps. Previous studies have shown that peptide hormones, including Ang II, can provoke changes in cell volume by affecting transmembrane ion fluxes in other types of cells (Lang et al., 1998; Fliegel and Karmazyn, 2004). It is therefore conceivable that a steepening of the slope of the relationship between cell volume and ECF osmolality could enhance osmosensory transduction in MNCs. However, our experiments indicated that Ang II does not affect osmometry in MNCs. Rather, it was found that Ang II increases the mechanosensitivity of MNCs and that this effect accounts quantitatively for the effect of the peptide on osmosensory transduction.

\section{Ang II potentiates mechanosensitivity via a PKC-mediated increase in cortical actin density}

Ang II was found to amplify mechanosensitivity through a signaling pathway involving PLC and a $\mathrm{Ca}^{2+}$-dependent form of PKC (i.e., either $\mathrm{PKC}_{\alpha}, \mathrm{PKC}_{\beta}$, or $\mathrm{PKC}_{\gamma}$ ) (Tanaka and Nishizuka, 1994). Furthermore, our results indicated that a PKCdependent modulation of the actin cytoskeleton is a key step in this process. Indeed, Ang II induced a significant PKCdependent increase in cortical F-actin density in MNCs (Fig. 6), and experiments with Cyt-D and JSK indicated that this increase in density is both necessary and sufficient to explain the effect of Ang II on mechanosensitivity in these cells (Fig. 7 ). How the increase in cortical actin density potentiates the mechanical activation of SIC channels remains to be deter-
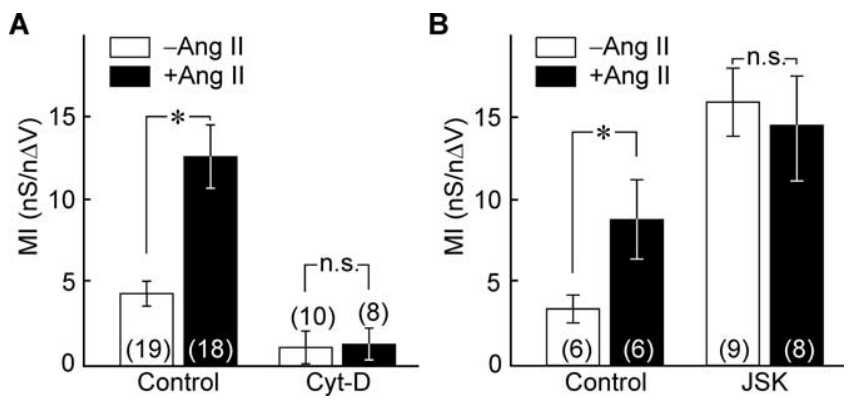

Figure 7. An increase in F-actin density mediates the effects of Ang Il on mechanosensitivity. Bar graphs plotting mean ( \pm SEM) values of Ml observed in the absence ( - Ang II; open bars) and presence of Ang II ( + Ang II; filled bars) under various conditions. $A$ compares the effects of these treatments in the absence (control; left) or presence (right) of Cyt-D. $B$ compares the effects of the treatments in the absence (left; control) or presence (right) of JSK. ${ }^{*} p<0.05$. n.s. Difference not statistically significant.

mined. The basis for the regulation of SIC channels during changes in cell volume is not known, but could involve a mechanically induced actin-dependent biochemical step (e.g., modulation of enzyme activity) or a more direct actindependent mechanical regulation of the SIC channels (Zhang et al., 2007). Whichever is the case, our results indicate that an increase in cortical actin density somehow facilitates this process. From a mechanistic viewpoint it is likely that Ang II mediates this effect by increasing the amount of force that is transmitted to the transduction apparatus per unit change in cell volume. This hypothesis is supported by experiments showing that the stiffness of a cross-linked actin network increases with the concentration of F-actin (Gardel et al., 2004; Shin et al., 2004). Thus, if a network of actin filaments relays volume-dependent mechanical forces to the transducer element, then the amount of force applied per unit volume change could increase with F-actin density and thus enhance 
transducer sensitivity, as was observed in the presence of Ang II and JSK.

\section{How does Ang II mediate an increase in cortical F actin density?}

In principle, a receptor-mediated $\mathrm{PKC}$-dependent increase in cortical F-actin density could be induced by the recruitment of F-actin into this subcellular compartment (Qian et al., 2002) or in response to an increase in the rate of local actin polymerization (Pilpel and Segal, 2004). However, the Ang IImediated increase in cortical F-actin density observed in MNCs was not accompanied by a concurrent decrease in the amount of F-actin in the cytoplasm (Fig. 6B). The effects of the peptide, therefore, may involve enhanced polymerization rather than an increase in cross-linking. Indeed, studies in cultured hippocampal neurons have shown that the activation of PKC can increase F-actin density by stimulating actin polymerization via RhoA and Racl (Pilpel and Segal, 2004), members of the Rho family of small GTPases. Moreover, G-protein-coupled receptors can mediate the activation of Rho GTPases (Kjoller and Hall, 1999; Sah et al., 2000), and Ang II has been shown to mediate a Rho-dependent increase in F-actin density in a variety of cell types (Aoki et al., 1998; Kuwahara and Kuwahara, 2002). Interestingly, a recent study has shown that $\beta$-arrestin 1 and $G_{\alpha q / 11}$ are both required for the Ang II-dependent activation of RhoA and resultant induction of stress fiber formation in HEK293 cells transfected with the $\mathrm{AT}_{1}$ receptor (Barnes et al., 2005). Strikingly, the authors showed that maximal activation of RhoA could occur within 1 min, a time course compatible with the rapid effects of Ang II on mechanosensitivity observed in our experiments. Additional studies will be required to investigate the possible involvement of Rho family GTPases in mediating the effects of Ang II on MNCs.

\section{References}

Akaishi T, Negoro H, Kobayasi S (1980) Responses of paraventricular and supraoptic units to angiotensin II, sar1-ile8-angiotensin II and hypertonic $\mathrm{NaCl}$ administered into the cerebral ventricle. Brain Res 188:499-511.

Aoki H, Izumo S, Sadoshima J (1998) Angiotensin II activates RhoA in cardiac myocytes: a critical role of RhoA in angiotensin II-induced premyofibril formation. Circ Res 82:666-676.

Barnes WG, Reiter E, Violin JD, Ren XR, Milligan G, Lefkowitz RJ (2005) beta-Arrestin 1 and Galphaq/11 coordinately activate RhoA and stress fiber formation following receptor stimulation. J Biol Chem 280:8041-8050.

Bleasdale JE, Bundy GL, Bunting S, Fitzpatrick FA, Huff RM, Sun FF, Pike JE (1989) Inhibition of phospholipase $\mathrm{C}$ dependent processes by U-73, 122. Adv Prostaglandin Thromboxane Leukot Res 19:590-593.

Bourque CW (2008) Central mechanisms of osmosensation and systemic osmoregulation. Nat Rev Neurosci 9:519-531.

Bourque CW, Ciura S, Trudel E, Stachniak TJ, Sharif-Naeini R (2007) Neurophysiological characterization of mammalian osmosensitive neurones. Exp Physiol 92:499-505.

Bubb MR, Senderowicz AM, Sausville EA, Duncan KL, Korn ED (1994) Jasplakinolide, a cytotoxic natural product, induces actin polymerization and competitively inhibits the binding of phalloidin to F-actin. J Biol Chem 269:14869-14871.

Chakfe Y, Bourque CW (2000) Excitatory peptides and osmotic pressure modulate mechanosensitive cation channels in concert. Nat Neurosci 3:572-579.

Cooper JA (1987) Effects of cytochalasin and phalloidin on actin. J Cell Biol 105:1473-1478

de Gasparo M, Catt KJ, Inagami T, Wright JW, Unger T (2000) International union of pharmacology. XXIII. The angiotensin II receptors. Pharmacol Rev 52:415-472.
Dunn FL, Brennan TJ, Nelson AE, Robertson GL (1973) The role of blood osmolality and volume in regulating vasopressin secretion in the rat. J Clin Invest 52:3212-3219.

Fliegel L, Karmazyn M (2004) The cardiac Na-H exchanger: a key downstream mediator for the cellular hypertrophic effects of paracrine, autocrine and hormonal factors. Biochem Cell Biol 82:626-635.

Gardel ML, Shin JH, MacKintosh FC, Mahadevan L, Matsudaira P, Weitz DA (2004) Elastic behavior of cross-linked and bundled actin networks. Science 304:1301-1305.

Hatae T, Kawano H, Karpitskiy V, Krause JE, Masuko S (2001) Argininevasopressin neurons in the rat hypothalamus produce neurokinin $\mathrm{B}$ and co-express the tachykinin NK-3 receptor and angiotensin II type 1 receptor. Arch Histol Cytol 64:37-44.

Herbert JM, Augereau JM, Gleye J, Maffrand JP (1990) Chelerythrine is a potent and specific inhibitor of protein kinase C. Biochem Biophys Res Commun 172:993-999.

Hussy N, Deleuze C, Desarménien MG, Moos FC (2000) Osmotic regulation of neuronal activity: a new role for taurine and glial cells in a hypothalamic neuroendocrine structure. Prog Neurobiol 62:113-134.

Ishibashi S, Oomura Y, Gueguen B, Nicolaidis S (1985) Neuronal responses in subfornical organ and other regions to angiotensin II applied by various routes. Brain Res Bull 14:307-313.

Jhamandas JH, Lind RW, Renaud LP (1989) Angiotensin II may mediate excitatory neurotransmission from the subfornical organ to the hypothalamic supraoptic nucleus: an anatomical and electrophysiological study in the rat. Brain Res 487:52-61.

Kjoller L, Hall A (1999) Signaling to Rho GTPases. Exp Cell Res 253:166-179.

Kuwahara M, Kuwahara M (2002) Involvement of Rho and tyrosine kinase in angiotensin II-induced actin reorganization in mesothelial cells. Eur J Pharmacol 436:15-21.

Lang F, Busch GL, Ritter M, Völkl H, Waldegger S, Gulbins E, Häussinger D (1998) Functional significance of cell volume regulatory mechanisms. Physiol Rev 78:247-306.

Mason WT (1980) Supraoptic neurones of rat hypothalamus are osmosensitive. Nature 287:154-157.

Moellenhoff E, Blume A, Culman J, Chatterjee B, Herdegen T, Lebrun CJ, Unger T (2001) Effect of repetitive icv injections of ANG II on c-Fos and $\mathrm{AT}_{1}$-receptor expression in the rat brain. Am J Physiol Regul Integr Comp Physiol 280:R1095-R1104.

Morris M, Li P, Callahan MF, Oliverio MI, Coffman TM, Bosch SM, Diz DI (1999) Neuroendocrine effects of dehydration in mice lacking the angiotensin AT1a receptor. Hypertension 33:482-486.

Nicolaidis S, Ishibashi S, Gueguen B, Thornton SN, de Beaurepaire R (1983) Iontophoretic investigation of identified $\mathrm{SFO}$ angiotensin responsive neurons firing in relation to blood pressure changes. Brain Res Bull 10:357-363.

Oliet SH, Bourque CW (1993) Mechanosensitive channels transduce osmosensitivity in supraoptic neurons. Nature 364:341-343.

Oliet SH, Bourque CW (1996) Gadolinium uncouples mechanical detection and osmoreceptor potential in supraoptic neurons. Neuron $16: 175-181$.

Pilpel Y, Segal M (2004) Activation of PKC induces rapid morphological plasticity in dendrites of hippocampal neurons via Rac and Rhodependent mechanisms. Eur J Neurosci 19:3151-3164.

Potts PD, Ludbrook J, Gillman-Gaspari TA, Horiuchi J, Dampney RA (2000) Activation of brain neurons following central hypervolaemia and hypovolaemia: contribution of baroreceptor and non-baroreceptor inputs. Neuroscience 95:499-511.

Qian Y, Baisden JM, Cherezova L, Summy JM, Guappone-Koay A, Shi X, Mast T, Pustula J, Zot HG, Mazloum N, Lee MY, Flynn DC (2002) PC phosphorylation increases the ability of AFAP-110 to cross-link actin filaments. Mol Biol Cell 13:2311-2322.

Renaud LP, Rogers J, Sgro S (1983) Terminal degeneration in supraoptic nucleus following subfornical organ lesions: ultrastructural observations in the rat. Brain Res 275:365-368.

Robertson GL, Athar S (1976) The interaction of blood osmolality and blood volume in regulating plasma vasopressin in man. J Clin Endocrinol Metab 42:613-620.

Robertson GL, Shelton RL, Athar S (1976) The osmoregulation of vasopressin. Kidney Int 10:25-37. 
Sah VP, Seasholtz TM, Sagi SA, Brown JH (2000) The role of Rho in G protein-coupled receptor signal transduction. Annu Rev Pharmacol Toxicol 40:459-489.

Sgro S, Ferguson AV, Renaud LP (1984) Subfornical organ-supraoptic nucleus connections: an electrophysiologic study in the rat. Brain Res 303:7-13.

Shin JH, Gardel ML, Mahadevan L, Matsudaira P, Weitz DA (2004) Relating microstructure to rheology of a bundled and cross-linked F-actin network in vitro. Proc Natl Acad Sci U S A 101:9636-9641.

Sladek CD, Blair ML, Ramsay DJ (1982) Further studies on the role of angiotensin in the osmotic control of vasopressin release by the organcultured rat hypothalamo-neurohypophyseal system. Endocrinology 111:599-607.

Tanaka C, Nishizuka Y (1994) The protein kinase C family for neuronal signaling. Annu Rev Neurosci 17:551-567.
Verbalis JG (2003) Disorders of body water homeostasis. Best Pract Res Clin Endocrinol Metab 17:471-503.

Voisin DL, Bourque CW (2002) Integration of sodium and osmosensory signals in vasopressin neurons. Trends Neurosci 25:199-205.

Wilkin LD, Mitchell LD, Ganten D, Johnson AK (1989) The supraoptic nucleus: afferents from areas involved in control of body fluid homeostasis. Neuroscience 28:573-584.

Yang CR, Phillips MI, Renaud LP (1992) Angiotensin II receptor activation depolarizes rat supraoptic neurons in vitro. Am J Physiol 263:R1333-R1338.

Zhang Z, Bourque CW (2003) Osmometry in osmosensory neurons. Nat Neurosci 6:1021-1022.

Zhang Z, Kindrat AN, Sharif-Naeini R, Bourque CW (2007) Actin filaments mediate mechanical gating during osmosensory transduction in rat supraoptic nucleus neurons. J Neurosci 27:4008-4013. 